\title{
A TEORIA WEBERIANA NA INVENÇÃO DO BRASIL: UMA ANÁLISE DE RAÍZES DO BRASIL DE SÉRGIO BUARQUE DE HOLANDA
}

\author{
Adriana Duarte de Souza Carvalho
}

\section{RESUMO}

Esse artigo tem com objetivo entender como Sérgio Buarque de Holanda, em sua obra de maior proeminência dentro das Ciências Sociais, Raízes do Brasil, se apropriou de categorias weberianas para entender a formação da sociedade e das instituições políticas brasileiras. Além disso, mostramos como Holanda utilizou a metodologia weberiana em suas análises, especificamente a questão dos tipos ideais. Apontamos também que Holanda foi um cientista social que, como muitos em sua época, procuraram entender o suposto atraso da sociedade brasileira. Por fim, queremos analisar como Holanda utilizou o conceito weberiano de racionalidade em sua análise das instituições políticas brasileiras, que ele considerava irracionais. Dessa forma, podemos compreender como Holanda formulou sua teoria do atraso e postulou uma visão do Brasil que encarava o país como um desvio histórico que precisava ser corrigido.

Palavras-chave: pensamento social brasileiro; iberismo e americanismo; teoria weberiana; Raízes do Brasil.

\section{WEBER'S THEORY IN BRAZIL'S INVENTIONS: AN ANALYSIS OF RAÍZES DO BRASIL BY SÉRGIO BUARQUE DE HOLANDA.}

\begin{abstract}
This article aims at understading the way in which Sérgio Buarque de Holanda, in his work of greater proeminance within the Social Sciences, Raizes do Brasil, used Weber's categories to comprehend the formation of Brazilian society and political institutions. Moreover, we will show how Holand used Weber's theory in his analysis, specifically of the ideal types. We will also point out that Holand was a social scientist that, as many of his time, tried to undrestand the so called lateness of Brazilian society. Finally, we will be able to comprehend how Holanda elaborated his lateness theory and asserted a vision of Brazil that saw it as an historic deviance that need to be fixed.
\end{abstract}

Keywords: Brazilian social thought; Iberism and Americanism; Weber's theory; Raízes do Brazil. 


\section{Introdução}

Sérgio Buarque de Holanda foi correspondente internacional dos Diários Associados em Berlim, cidade que visitava esporadicamente para a realização de atividades acadêmicas. Foi nesse contexto que entrou em contato com a Sociologia alemã, especialmente com a obra do sociólogo alemão Max Weber, justamente entre 1929 e 1930. Raízes do Brasil foi publicada em 1936 e mostra claramente a marca que a sociologia weberiana deixou sobre Sérgio Buarque de Holanda.

A proposta desse trabalho é fazer uma análise da maneira pela qual Sérgio Buarque de Holanda, especificamente na sua obra de maior expressão dentro das Ciências Sociais brasileira, Raízes do Brasil, se apropriou de aspectos fundamentais da teoria weberiana para a compreensão da sociedade brasileira. Mais do que isso, pretende-se mostrar como Raízes do Brasil está fundamentada na própria metodologia weberiana e como o autor utiliza-se dela em sua análise da fundação da sociedade brasileira.

É principalmente através do conceito weberiano de racionalidade que Sérgio Buarque de Holanda tem a chave para a compreensão do Brasil, justamente para trazer à tona os elementos de irracionalidade ou do não-racional que ele localiza na sociedade brasileira. Enquanto Weber estava categoricamente afirmando que a racionalização burocrática é a característica mais marcante da sociedade moderna, Sérgio Buarque de Holanda estava mostrando que o problema da sociedade brasileira era justamente a falta de racionalização e, por isso, éramos uma sociedade atrasada. O autor utiliza, assim, os conceitos de iberismo e americanismos para explicar o atraso brasileiro.

O fato é que, na década de 30, muitos intelectuais estavam pensando o atraso na sociedade brasileira, justamente porque foi nesse momento em que mais intensamente foi colocada a questão da modernização do Brasil e em que o Estado empenhou -se para acelerar o ritmo dessa modernização. Sabe-se que não há, em Raízes do Brasil, a especificação clara de um projeto de modernização para o país, mas esse tema percorre toda a obra. De qualquer forma, Raízes do Brasil é um claro reflexo de sua época, em que se repensava o Estado brasileiro através do questionamento da política oligárquicaliberal da Primeira República. 
Além dos conceitos de racionalidade e de racionalização, Holanda passa ainda pela Sociologia da religião de Weber, principalmente aquela presente em A Ética Protestante e o Espírito do Capitalismo, pelos tipos ideais, pela questão da burocratização, do capitalismo nas sociedades modernas Ocidentais e do Estado nacional, fazendo uso freqüente do vocabulário weberiano.

Essa pesquisa mostrará, portanto, como Sérgio Buarque de Holanda, considerado por certa tradição das Ciências Sociais como um dos "inventores" do Brasil, se aproximou da teoria weberiana para a compreensão dos problemas de uma sociedade específica, em um momento específico - a sociedade brasileira no momento de sua fundação enquanto uma Nação, justamente como havia feito Weber com a Alemanha de sua época.

\section{A Metodologia Weberiana em Raízes do Brasil}

A questão da racionalidade atravessa toda a obra de Weber (1997) e é, sem dúvidas, um de seus conceitos mais importantes. A discussão weberiana sobre a racionalidade está intrinsecamente ligada à sua discussão da especificidade da sociedade Ocidental em relação às demais. Cohn (2003) mostra que o fator que permite a Weber compreender essa configuração histórica, própria da sociedade ocidental, é a análise de como ela incorporou o processo de racionalização. Apenas no mundo Ocidental encontramos Direito racional, arte racional, organização racional do trabalho, economia racional, religião racional e assim por diante. Sobre isso afirma Weber (1997:11)

\footnotetext{
Racionalizações têm existido em todas as culturas, no mais diversos setores e dos tipos mais diferentes. Para caracterizar sua diferença do ponto de vista da história da cultura, deve-se primeiro ver primeiro em que esfera e direção elas ocorreram. Por isso, surge novamente o problema de reconhecer a peculiaridade do racionalismo ocidental (...).
}

Holanda (2002) faz uso desse conceito weberiano de interpretação da sociedade ocidental, aplicando-o à realidade brasileira. Ele coloca-o diante da nossa sociedade como um espelho e aponta a racionalidade que faltava. Na verdade, ele explica nossa sociedade pela ausência de racionalidade e as consequiências implicadas por isso.

A obra Raízes do Brasil de Sérgio Buarque de Holanda está fundamentada metodologicamente sobre dualidades. Cohn (2003) mostra como isso também está posto 
na obra de Weber: "Com efeito, todo o arcabouço metodológico weberiano está construído sobre uma seqüência de dualidades, articuladas em torno de uma que é dominante: racional/não racional." (COHN, 2003, p. 8). Antonio Candido (2002), em seu prefácio à obra, cita alguns exemplos dessa análise dualista empregada por Holanda: trabalho e aventura, método e capricho, rural e urbano, burocracia e caudilhismo, norma impessoal e impulso afetivo. É preciso acrescentar, além dessas, a dualidade que mais marcadamente apresenta-se no livro: iberismo e americanismo, por meio da qual Sérgio Buarque de Holanda analisa categoricamente a formação da sociedade brasileira. A discussão sobre a dualidade iberismo e americanismo estabelece uma discussão com a questão da racionalidade em Weber e é aquela que mais exemplifica a distinção estabelecida por Weber entre o irracional e o racional, considerando que nossa herança ibérica seria portadora de uma irracionalidade, a razão do nosso atraso e, portanto, deveríamos almejar alcançar o americanismo, que tem como principal característica a racionalidade.

A dualidade iberismo/americanismo não está, contudo, isenta de ambigüidades, já que Holanda consegue imprimir certo valor a algumas características da herança ibérica brasileira, apesar de explicitamente criticá-la. Piva (2000) localiza essa ambigüidade no capítulo IV de Raízes do Brasil, intitulado "O Semeador e o Ladrilhador". Essa é, novamente, uma construção típico-ideal. Nesse capítulo, Holanda (2002) compreende que só a razão poderia trazer a modernização da sociedade brasileira. O Ladrilhador é justamente o elemento da racionalidade, ausente na sociedade brasileira. Ele tornaria nossa esfera pública impessoal, tornando possível a democracia. No entanto, Holanda vê na figura do Semeador um elogio à autenticidade brasileira, é uma defesa daquilo que é nosso. Nas palavras de Piva (2000, p.155)

\footnotetext{
Holanda quer os dois ao mesmo tempo. (...) Nesse cruzamento emerge uma tensão na avaliação da herança ibérica, que é importada, transplantada, mas é constitutiva, é a base da nacionalidade, responsável pelos aspectos negativos diagnosticados (são as "raízes do Brasil"), porém vista não como algo estranho a ser extirpado, mas sim de dentro da qual se devem extrair nossas peculiaridades positivas.
}

Holanda (2002) vai, então, procurar a origem desses males presentes na sociedade brasileira. Neste empreendimento ele acaba fazendo uma análise das recorrências. Ele procurava aquilo que se repetia na história brasileira. Ele localiza essa recorrência justamente no iberismo, a marca do nosso atraso e irracionalidade. Piva 
(2000) mostra o caminho metodológico seguido por Holanda (2002). Ele se foca, em um primeiro momento, na sociedade brasileira do presente, marcada pelo clientelismo, caudilhismo, paternalismo e patrimonialismo. Em seguida, ele tenta encontrar alguns elementos que explicam seu atraso. Finalmente, ele localiza esses elementos na nossa cultura ibérica. Nesse sentido, é importante atentar mais demoradamente sobre o que Holanda (2002) chama de iberismo e porque o autor considerava necessário superá-lo.

É evidente como essa metodologia dos contrários, presente na obra de Holanda (2002), também está fundamentada nas construções dos tipos ideais weberianos. Cohn (1979, p. 8) define os tipos ideais weberianos:

Trata-se de um recurso metodológico para ensejar a orientação do cientista no interior da inesgotável variedade de fenômenos observáveis na vida social. Consiste em enfatizar determinados traços da realidade (...) até concebê-los na sua expressão mais pura e conseqüente, que jamais se apresenta assim nas situações efetivamente observáveis. Por isso mesmo esses tipos necessitam serem construídos no pensamento do pesquisador, existem no plano das idéias sobre os fenômenos e não nos próprios fenômenos.

Vamos pensar, para exemplificar a afirmação acima, nos tipos ideais do trabalhador e do aventureiro. Holanda (2002) especifica claramente que o aventureiro representa o português e o trabalhador o espanhol, ambos localizados pelo autor no período colonial. As características desses tipos marcaram profundamente o tipo de colonização que os dois povos estabeleceram. Holanda (2002) aponta que a exploração do Brasil pelo português aventureiro não foi um empreendimento metódico e racional e que o brasileiro é herdeiro deste tipo. Desta maneira, o homem brasileiro é irresponsável, instável e avesso à idéia de trabalho. O que lhe agrada é a idéia de prosperar sem custo e obter riquezas fáceis. Para o autor, essas características tiveram influência decisiva na nossa vida nacional. Enquanto o tipo ideal trabalhador é aquele que se esforça, que é persistente e sabe tirar proveito do insignificante, os brasileiros são indolentes.

\section{O Iberismo e a formação do homem cordial}

Segundo Souza (2000:161): “O ponto zero da constituição da sociedade brasileira para Buarque é marcado pela circunstância de termos recebido nossa herança européia de uma nação ibérica.” 
Em toda a sua obra Holanda (2002) vai tentar reconstruir os elementos dessa herança que são constitutivos da nossa nacionalidade e que moldam nossas instituições políticas. É preciso lembrar, portanto, que é justamente na década de 30 - momento em que Raízes do Brasil está sendo escrita - que a Questão Nacional e a modernização do país estão sendo pensadas por muitos intelectuais e pela elite que está no poder. O próprio aparelho de Estado sofre um importante processo de burocratização e mudanças legislativas que garantiam mais direitos à população começam a ocorrer.

Holanda (2002) enfatiza que a imposição da cultura portuguesa através da colonização foi um fato marcante nas origens da sociedade brasileira. Justamente por isso o autor vai analisar cuidadosamente algumas características de Portugal e questionar até que ponto os brasileiros estavam aptos a conviver com essa herança ibérica.

O elemento mais marcante que Portugal legou à sua colônia foi a cultura da personalidade, que Holanda (2002) também chama de personalismo. A cultura da personalidade poderia ser explicada como um excepcional valor dado à pessoa humana e à sua respectiva autonomia em relação aos demais indivíduos que formam determinada sociedade, não havendo, portanto, a produção de uma solidariedade social. É importante, no entanto, não confundir cultura da personalidade com individualismo liberal. $\mathrm{O}$ autor relata que a burguesia mercantil portuguesa, ao contrário, por exemplo, da burguesia inglesa, não procurou novos valores, especificamente, os valores do calvinismo ascético, para se legitimar como classe social. A burguesia portuguesa se aliou às antigas classes dirigentes e negligenciou aquela razão fria e calculista que é marca tão característica do capitalismo calvinista mostrado por Weber. Pode-se afirmar que Portugal não teria sido "contaminado" pela ética protestante; é só lembrar como Portugal foi profundamente influenciado pelo pensamento escolástico até as reformas pombalinas na segunda metade do século XVIII.

De acordo com Holanda (2002), esse personalismo teria se institucionalizado na sociedade brasileira, dando origem a uma série de problemas: o maior deles seria, sem dúvidas, a falta de coesão social. É interessante observar como Buarque está também buscando certo vocabulário durkheimiano quando fala em coesão social e solidariedade social. É mais que evidente que nosso personalismo seria a marca mais autêntica da nossa falta de racionalidade - agora nos termos weberianos. A cultura da personalidade é o oposto de qualquer forma de racionalização e, definitivamente, é um tipo de sociabilidade que não pode conviver com a democracia. É interessante como Sérgio 
Buarque também está se focando nos problemas da democracia no Brasil e como, nesse sentido, ele acaba fazendo uma Sociologia das instituições políticas.

A análise do personalismo acaba levando o autor a criar o conceito de homem cordial, que é o fruto da nossa história, da colonização portuguesa, de uma sociedade rural, patriarcal e escravocrata. Este homem tem como características principais a hospitalidade e a generosidade. Estas virtudes poderiam facilmente ser confundidas com a civilidade, mas na verdade significam que o homem cordial possui um fundo emotivo muito rico. Esse é o personagem mais característico de uma sociedade patrimonialista, de uma sociedade que ainda não passou pelo processo de racionalização. Nas palavras de Holanda (2002:147): “Armado dessa máscara (a cordialidade), o indivíduo consegue manter sua supremacia ante o social. E, efetivamente, a polidez implica uma presença contínua e soberana no indivíduo.”

Essa abordagem da personalidade brasileira mais uma vez leva o autor a entender o Estado brasileiro: trata-se do Estado patrimonialista, em que o público se confunde com o privado, pois este nada mais é do que uma ampliação do circulo familiar, que o homem cordial não é capaz de romper para consolidar o Estado racional moderno.

As conseqüências da cultura da personalidade ultrapassam as nossas instituições políticas. Para compreender essa questão é necessário voltar para a análise feita por Weber sobre o capitalismo moderno. De acordo com essa concepção, o surgimento do capitalismo moderno teria sido fruto do desenvolvimento de uma nova atitude em relação ao trabalho. O protestantismo ascético, em sua versão calvinista, teria sido responsável pela divulgação de uma ética do trabalho, que teria justificado e possibilitado a acumulação capitalista, pois o calvinismo entende que o trabalho secular tem um valor moral.

Holanda (2002) observa que essa nova postura em relação ao trabalho não nos foi legada pelos portugueses; isso é evidente quando pensamos que a religião que predominou em Portugal foi o catolicismo. Nossos colonizadores não teriam aderido a essa nova ética que foi configurada com a Reforma Protestante. De fato, o autor afirma que para os brasileiros as profissões são meros acidentes. Segundo Holanda (2002, p.45) o que predominou entre nós foi uma ética da aventura, não uma ética do trabalho:

Existe uma ética do trabalho, como existe uma ética da aventura. Assim, o indivíduo trabalhador só atribuirá valor moral positivo às ações que sente ânimo de praticar e, inversamente, terá por imorais e detestáveis as 
qualidades próprias da aventura _ audácia, imprevidência, irresponsabilidade, instabilidade, vagabundagem — tudo, enfim, quanto se relacione com a concepção espaçosa do mundo, característica desse tipo.

Como já foi mencionada acima, Raízes do Brasil apresenta algumas ambigüidades. Na discussão da ética do trabalho e da aventura podemos notar mais uma. Para Holanda (2002), a ética da aventura implica em conseqüências positivas e negativas sobre nossa vida nacional. A própria ausência da ética do trabalho é esse fator negativo. Mas são os fatores positivos que se destacam. O gosto pela aventura foi essencial para o processo de adaptação nas terras brasileiras, além de favorecer a mobilidade social.

As conseqüências do personalismo estão em toda a análise de Holanda (2002). Segundo o autor, elas se manifestam em toda a dinâmica da vida do brasileiro. Também se manifesta no mercado, impedindo o desenvolvimento de um capitalismo mais maduro, se manifesta na religião, implicando em uma visão específica de divindade, em um catolicismo mágico. Holanda (2002, p.151), no entanto, ainda encontra a chave para se pensar o futuro da nação em uma certa flexibilidade que ele coloca da seguinte forma:

A vida íntima do brasileiro nem é bastante coesa, nem bastante disciplinada,
para envolver e dominar toda a sua personalidade, integrando-a, como peça
consciente, no conjunto social. Ele é livre, pois, para se abandonar a todo o
repertório de idéias, gestos e formas que encontre em seu caminho,
assimilando-os freqüentemente sem maiores dificuldades.

Souza (2001) apresenta um desafio aos intelectuais da sociedade brasileira. Fazse necessário, segundo ele, encontrar novas explicações para o atraso social e político da sociedade brasileira. Ele cita alguns autores, entre eles o próprio Holanda, além de Faoro e Da Matta, que criaram uma explicação para o Brasil sempre enfatizando as marcas da herança ibérica na formação da sociedade brasileira. Nas palavras de Souza (2001: p.58)

De acordo com essa concepção, que poderíamos chamar de nossa "sociologia da inautenticidade", o Brasil é o "outro" ou um desvio da modernidade, tendo sido modernizado para "inglês ver", uma modernização epidérmica e de fachada.

Souza (2001) aponta alguns caminhos para uma nova compreensão do Brasil. Em primeiro lugar é preciso considerar como os valores são institucionalizados pela 
sociedade. E, em seguida, vincular essa relação valores/institucionalização, com a questão da estratificação social. Essa perspectiva permite notar as complexidades e dinamismos da sociedade brasileira, entendendo-a como uma peculiaridade no processo de modernização e não apenas um desvio histórico.

\section{O Estado Moderno e o Estado Patrimonialista}

Uma contribuição fundamental da obra weberiana é sua teoria política. Sua definição do Estado moderno é largamente estudada e aceita. Vamos entender como Weber constrói essa definição. Em primeiro lugar, Weber afirma que o Estado não se define pelos seus fins, mas sim pelo seu meio específico, que é o monopólio do uso legítimo da violência. Weber também aponta que o Estado é uma instituição de dominação, em que se faz necessário um estado-maior administrativo e meios materiais de gestão. Weber (2000, p. 62) define o Estado Moderno:

(...) é um agrupamento de dominação que apresenta caráter institucional e que procurou (com êxito) monopolizar, nos limites de um território, a violência física legítima como instrumento de domínio e que, tendo esse objetivo, reuniu nas mãos dos dirigentes os meios materiais de gestão. Equivale isso a dizer que o estado moderno expropriou todos os funcionários que, segundo o princípio dos "Estados" dispunham outrora, por direito próprio de meio de gestão, substituindo-se tais funcionários, inclusive no topo da hierarquia.

A teoria weberiana de Estado está colada à sua teoria dos tipos de dominação. Quando Weber constrói os três tipos de dominação - ou de legitimidade - ele destaca que o Estado Moderno democrático sustenta-se no tipo racional-legal. Vamos nos atentar para as palavras do próprio Weber (2000, p.58):

Existe, por fim, a autoridade que se impõe em razão da "legalidade", em razão da crença na validez de um estatuto legal e de uma competência positiva, fundada em regras racionalmente estabelecidas ou, em outros termos, a autoridade fundada na obediência, que reconhece obrigações conformes ao estatuto estabelecido. Tal é o poder, como o exerce o "servidor do Estado" em nossos dias e como o exercem todos os detentores do poder que dele se aproximam sob esse aspecto.

A argumentação de Holanda segue no sentido de que no Brasil a predominância do personalismo impediu que esse tipo de Estado descrito por Weber - um Estado racional - pudesse existir, pelo menos até a época em que a obra estava sendo escrita. É 
justamente nesse sentido que Holanda vai empreender uma análise das instituições políticas brasileiras, procurando pelos elementos não-racionais dessas instituições que seriam fruto da nossa cultura da personalidade. Concomitantemente há, em Raízes do Brasil, uma crítica à democracia no Brasil, que é tida por Holanda como um lamentável mal-entendido. Sua análise de alguns movimentos marcantes na história do país é bastante pessimista, já que não foram promovidos pelo povo, mas sim pela elite no poder.

Weber destacava como característica fundamental do Estado Moderno democrático a impessoalidade. Um Estado democrático elimina o exercício do privilégio ao primar pela representação política e pela igualdade perante a lei. Dessa forma, o autor estabelece uma relação entre o crescimento do Estado burocrático e o crescimento da democracia política.

Holanda (2002), indo além, vai mostrar como o Estado Moderno só pode se estabelecer à medida que transgride a ordem familiar, onde predomina a pessoalidade. De acordo com Holanda (2002, p.14):

O Estado não é uma ampliação do círculo familiar e, ainda menos, uma integração de certos agrupamentos, de certas vontades particularistas, de que a família é o melhor exemplo. Não existe, entre o círculo familiar e o Estado, uma gradação, mas antes uma descontinuidade e até uma oposição.

Segundo Holanda, não teria ocorrido essa transgressão na sociedade brasileira, ou seja, o Estado não teria rompido com a família, o que implica, necessariamente, que as relações de sangue não foram substituídas por instituições e relações sociais impessoais. Mais do que isso, o caráter das leis não é universal, já que elas só são aplicadas àqueles que se encontram fora desses círculos de parentesco e amizade. Toda a base em que se fundamenta a argumentação de Holanda de que o Brasil deveria aspirar ao americanismo é justamente essa: que as instituições políticas e as relações sociais norte-americanas se pautam pela impessoalidade e, por isso, são mais democráticas. De acordo Holanda (2002, p.15):

Essa aptidão para o social está longe de constituir um fator apreciável de ordem coletiva. Por isso mesmo que relutamos em aceitar um princípio superindividual de organização (...) toda a nossa conduta denuncia, com freqüência, um apego singular aos valores da personalidade configurada pelo recinto doméstico. Cada indivíduo, nesse caso, afirma-se ante os seus semelhantes indiferente à lei geral, onde esta lei contrarie suas afinidades emotivas (...). 
Mas a análise de Holanda vai ainda mais longe. Que tipo de Estado uma sociedade que se pauta pela cultura da personalidade poderia estabelecer? $\mathrm{O}$ autor responde: um Estado patrimonialista. Novamente Holanda utiliza aqui um conceito weberiano para pensar no Brasil. Trata-se do conceito de funcionário patrimonial, que utiliza a gestão pública para atender interesses particulares.

Giddens (2000) procura analisar a compreensão weberiana de patrimonialismo. Em primeiro lugar é necessário destacar que o patrimonialismo foi considerado por Weber como um tipo de dominação tradicional marcadamente paternalista. De acordo com Giddens (2000, p.219): “A autoridade tradicional baseia-se na crença na santidade das regras e poderes há muito estabelecidos." $\mathrm{Na}$ sociedade patrimonialista o corpo administrativo desenvolve uma fidelidade pessoal com o chefe. Como contrapartida, eles ganham uma série de privilégios. $\mathrm{Na}$ verdade, esse corpo administrativo tem relação de consangüinidade ou de amizade com o líder. O recrutamento desses funcionários não se dá por comprovação de competência, mas por laços afetivos.

Ele destaca que o predomínio da família patriarcal gera um desequilíbrio, ou seja, aqueles que ocupavam posições públicas no Brasil não eram capazes de distinguir entre os domínios públicos e privados. Holanda (2000, p.146) afirma: “Assim, eles se caracterizam justamente pelo que separa o funcionário 'patrimonialista' do puro burocrata conforme a definição de Max Weber." Observa-se aqui uma sociedade onde o público não se distingue do privado, uma vez que o público é o lugar onde os interesses da família patriarcal são realizados, onde predomina uma solidariedade entre parentes e amigos, na qual interesses particularistas se realizam em detrimento da realização da vontade geral da sociedade. Vamos nos atentar mais profundamente pela forma como Weber (1974, p.22) entende o Estado democrático “O Estado democrático, assim como o Estado absoluto, elimina a administração feudal, patrimonial, patrícia, ou de outros dignitários que exercem o poder de forma honorária ou hereditária, e a substitui por funcionários civis.".

Para Weber, a burocratização é uma característica inerente ao Estado democrático moderno. Mas o fato é que, de acordo com Holanda, ainda não tínhamos instituições políticas democráticas. Como não é possível instituir-se uma gestão pública meritocrática sem a concomitante democratização do sistema político, criou-se no Brasil mecanismos de administrar o público baseado em privilégios, não no mérito. 


\section{Conclusão}

Como essa pesquisa deixou claro, o conceito de racionalização perpassa toda a teoria weberiana. Weber afirmava categoricamente que o processo de racionalização é inevitável na história. Nogueira (1997, p.139) mostra que o processo de racionalização, de acordo com Weber é: “(...) considerado por ele como o fundamento, a essência e o'fio condutor' da história da economia e da sociedade 'moderna'. O conceito de racionalização é o núcleo de sua concepção de mundo."

Considerando a análise de Holanda (2002), percebemos que o Brasil seria um desvio desse processo, que precisaria ser corrigido. E, mais uma vez, nos remetemos para o conceito de americanismo, que tem como característica principal a racionalidade. É necessário considerar, no entanto, que a própria análise weberiana sobre a racionalização é problemática. Nogueira (1997) afirma que Weber se coloca acima das particularidades históricas de cada sociedade ao considerar a racionalização como uma inevitabilidade histórica.

Holanda (2002), embora considere as peculiaridades históricas da sociedade brasileira - o iberismo, o personalismo e o predomínio da vida rural e patriarcal - ainda remete constantemente para a nossa falta de racionalidade, considerando o Brasil um desvio de padrão normal de desenvolvimento da racionalidade e da própria modernidade. Assim, em Holanda (2002) o processo de racionalização não é uma inevitabilidade histórica. Pelo contrário, a presença ou não de racionalidade depende de particularidades dadas historicamente.

De qualquer maneira, é necessário admitir que Holanda (2002) tinha expectativas otimistas em relação à modernização do país. A fuga do iberismo se daria com o fim das bases rurais e com o crescimento da vida urbana e pública, como coloca Piva (2000). Tendo em vista as transformações pelas quais passava o aparelho de Estado brasileiro no período de publicação da obra, por meio da criação de um aparelho de Estado moderno e burocratizado, podemos entender o otimismo do autor. 


\section{Referências Bibliográficas}

COHN, Gabriel. Crítica e Resignação. São Paulo: Martins Fontes: 2003. 256 p.

DIGGINS, John Patrick. Max Weber - A Política e o Espírito da Tragédia. Tradução Liszt Viera e Marcus Lessa. São Paulo: Record, 1999.

GIDDENS, Anthony. Capitalismo e Moderna Teoria Social. Tradução Maria do Carmo Cary. Lisboa: Presença, 2000. 335 p.

HOLANDA, Sérgio Buarque de. Raízes do Brasil. São Paulo: Companhia da Letras, 2002. $220 \mathrm{p}$.

NOGUEIRA, Marco Aurélio. Max Weber: a Burocracia e as Armadilhas da Razão. Coleção Temas de Ciências Humanas. Editorial Grijalbo, 1980. 185 p.

SOUZA, Jessé. A Modernização Seletiva - uma reinterpretação do dilema brasileiro. Brasília: Editora da Universidade de Brasília, 2000. 276 p.

A Sociologia Dual de Roberto Da Matta: descobrindo nossos mistérios ou sistematizando nossos auto-enganos? RBCS Vol. 16 número 45 fevereiro/2001. p 4767.

PIVA, Luiz Guilherme. Ladrilhadores e Semeadores: a modernização brasileira no pensamento de Oliveira Vianna, Sérgio Buarque de Holanda, Azevedo Amaral e Nestor Duarte. (1920-1940). São Paulo: Editora 34, 2000. 262 p.

WEBER, Max. A Ética Protestante e o Espírito do Capitalismo. São Paulo: Livraria Pioneira Editora, 1997. 233 p.

. Ciência e Política - duas vocações. São Paulo: Cultrix, 2000. 124 p.

Parlamentarismo e Governo numa Alemanha Reconstruída. In: WEBER, Max. Ensaios de Sociologia e outros escritos. São Paulo: Abril Cultural, 1974. Coleção os Pensadores. 270 p.

. Sociologia. Gabriel Cohn (Org.). Amélia Cohn (Trad.). São Paulo: Ática, 1979. v.13. 168 p. (Coleção Grandes Cientistas Sociais; v.13)

Departamento Administrativo do Serviço Público (DASP), disponível em www.cpdoc.fgv.br, acessado em 09 de julho de 2006. 